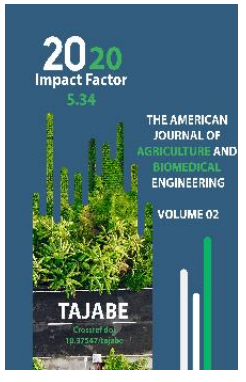

Copyright: Original content from this work may be used under the terms of the creative commons attributes 4.0 licence.

\section{Pest Of Calendula Officinalis L. And Control Measures In Kashkadarya Region}

\author{
Davlatbek Nazaralievich Ruzikulov \\ Professor, Researcher Of The Department Of Plant Protection Tashkent State Agrarian \\ University, Tashkent, Uzbekistan
}

Xonoyim Abduqaxxorovna Ergasheva

Tashkent State Agrarian University, Tashkent, Uzbekistan

\title{
ABSTRACT
}

In this article presents the results of research of pests in medicinal plants grown in the Uzbekistan. During the study, polyphagous and oligophagous pests were found in medicinal plants, worm (orexotvorka), cotton nightshade, marmara nightshade,thrips, mint flea, rosemary baridi, rosemary juice, rosemary stalk, valerian juice.

\section{KEYWORDS}

Medicinal plants, pest, entomophagous, degree of damage, biological effectiveness.

\section{INTRODUCTION}

It is known that today the republic is taking a number of measures to establish plantations of medicinal cloves (calendula officinalis I.), therefore, it is important to study the species composition, biological and ecological characteristics of pests that cause plant death in these crops, and to drastically reduce the damage caused by them.

Today, in order to develop the pharmaceutical industry, provide the population with natural medicines and improve the health of the population, special attention is paid to the 
cultivation of medicinal plants in the areas specializing in medicinal crops located in the territory of the Republic. Therefore, including in several provinces; In order to cultivate medicinal crops in forestry crops of Tashkent, Jizzakh, Samarkand, Kashkadarya, Surkhandarya and a number of other regions and to increase the quantity and quality of crops, areas have been allocated for planting medicinal crops.

With the expansion of the area under medicinal crops, the species composition of pests that cause damage to these plants is also increasing.

Growing natural medicines, on the other hand, requires being environmentally friendly. One of the main factors in obtaining high yields from medicinal plants is their protection from pests. The topical issue is the effective implementation of effective control measures for the protection of medicinal plants from pests (Ahmedov O., Ergashev A., Abzalov A., Yulchieva M.) [1]

In recent times, there are several types of pests in medicinal plants that are useful in maintaining the health of the population, and as a result of their damage, a significant part of the crop can be lost.

In order to obtain high and high-quality yields from medicinal plants established in the country, from early spring to early ripening, the species composition, distribution, damage period, degree of damage, bioecological characteristics of various pests in the climatic conditions of the republic, high biological and the development and implementation of a cost-effective, coordinated system of struggle is one of the important tasks of today. Based on the above problems, medicinal plants established in the forestry areas are grown such crops as cloves, peppermint, chakanda,
Turkestan lion's tail, namatak, medicinal mavrak, Turkestan hawthorn, dalachay, kyzylpoycha, chayoti, thorny kavul (Dusmanov A., 2015) [2].

According to research conducted in the country, the main medicinal plant (Salendula officinalis I.) Has been observed to infect the roots and upper parts of plants with various pests and diseases. If the vegetative part of the nail is severely damaged by melon juice, the cotton nightshade causes great damage to the generative organs. In addition, this plant is a favorite food of field lizards and crabs, spiders, rodents and locusts.

Damage to medicinal plants by pests adversely affects their medicinal and physiological properties, slows their growth, reduces productivity, leads to the complete destruction of some parts or the plant.

When analyzing the literature for the study of the species composition of pests of medicinal plants in the country, it is important to conduct research on the biological and ecological characteristics of pests of these crops in Uzbekistan, their distribution, degree of damage and quantity management. To this end, we conducted our research on the development of methods for managing the species composition and quantity of medicinal plant pests that are medicinal to human health in forests.

\section{RESEARCH MATERIALS AND METHODS}

The research was conducted in the forestry areas of Kamashi and Yakkabag districts of Kashkadarya region, which specialize in the cultivation of medicinal plants.

As a result of the conducted research (20182020), the species of insects that cause damage to the medicinal plant of the introduced nail care and their composition 
The American Journal of Agriculture and Boimedical Engineering (ISSN - 2689-1018)

Published: October 29, 2020 | Pages: 46-50

Doi: https://doi.org/10.37547/tajabe/Volume02Issue10-08

were identified. It also studied the population level of some species, their distribution, the peculiarities of the ecology of the most important species and non-traditional methods of pest control. Studies of pests on nail plantations in forestry in Kamashi district, Kashkadarya region, have shown that their fauna consists mainly of species that damage not only nails, but also ornamental plants, fruit trees, as well as shrubs.

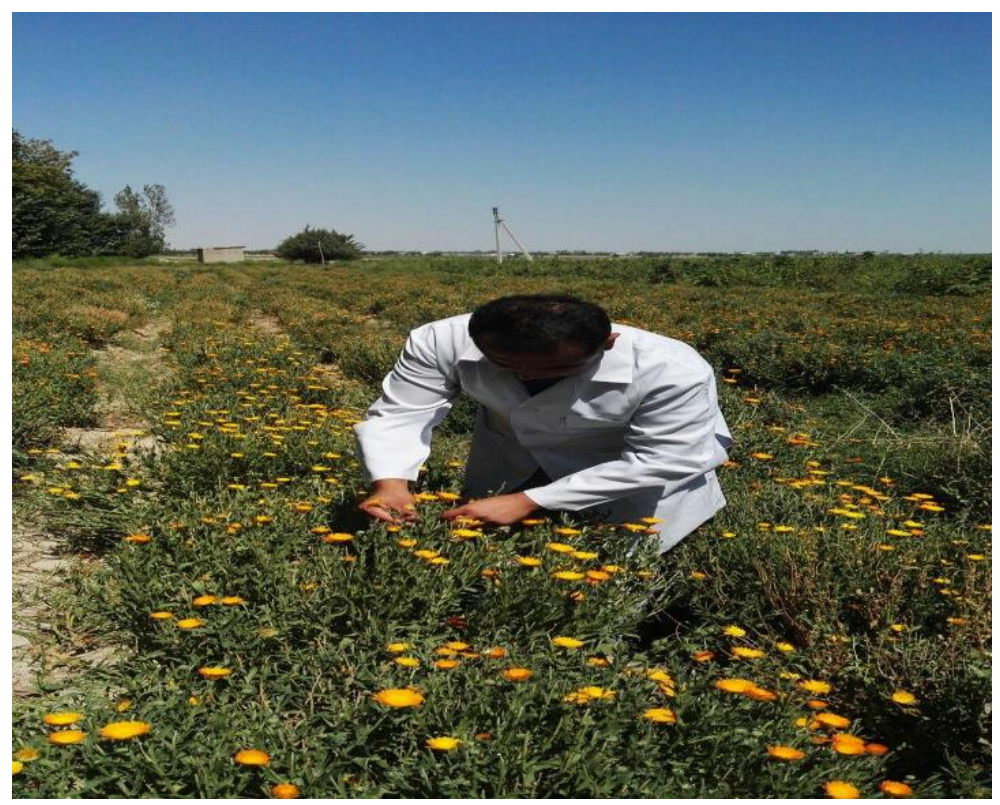

Figure 1. Medicinal nail plantation planted in the forestry of Kamashi district, Kashkadarya region (2020).

The effect of temperature on the development of insects was studied in special thermostats with constant humidity $65-70 \%$.

The species, bioecology, dominant distribution and damage caused by pests were studied (G.Ya. Bey-Bienko, S.M. Volkov et al., V.I. Tansky et al., L.M. Kopaneva).

Temporary drugs are made from live insects. To do this, Hoer liquid (Berleza liquid) is applied to the subject glass (dripped, insect repellent is placed on it, and a closed glass is placed and heated until it shines. But the drug is not suitable for long-term storage (E.M. Dantsig, 1993).
During our research, oligophagous and polyphagous pests such as cotton bollworm, cotton bollworm, marble thrips, mint thrips, mint flea, rosehip baridi, rosehip sap, valerian juice, which specialize in medicinal plants, were identified.According to the results of our scientific research, polyphagous pests also cause a lot of damage, along with specialized pests in each of the medicinal plants.

During our observations, 8 species of specialized and 22 species of oligopolyphagous pests were identified.

\section{EXPERIMENTAL RESULTS.}

1. Brown shira - Chaitophorus capreae Mosl. Distributed in all regions of Uzbekistan. Juices 
The American Journal of Agriculture and Boimedical Engineering (ISSN - 2689-1018)

Published: October 29, 2020 | Pages: 46-50

Doi: https://doi.org/10.37547/tajabe/Volume02Issue10-08

suck under the leaves of cloves and cause damage and form colonies.

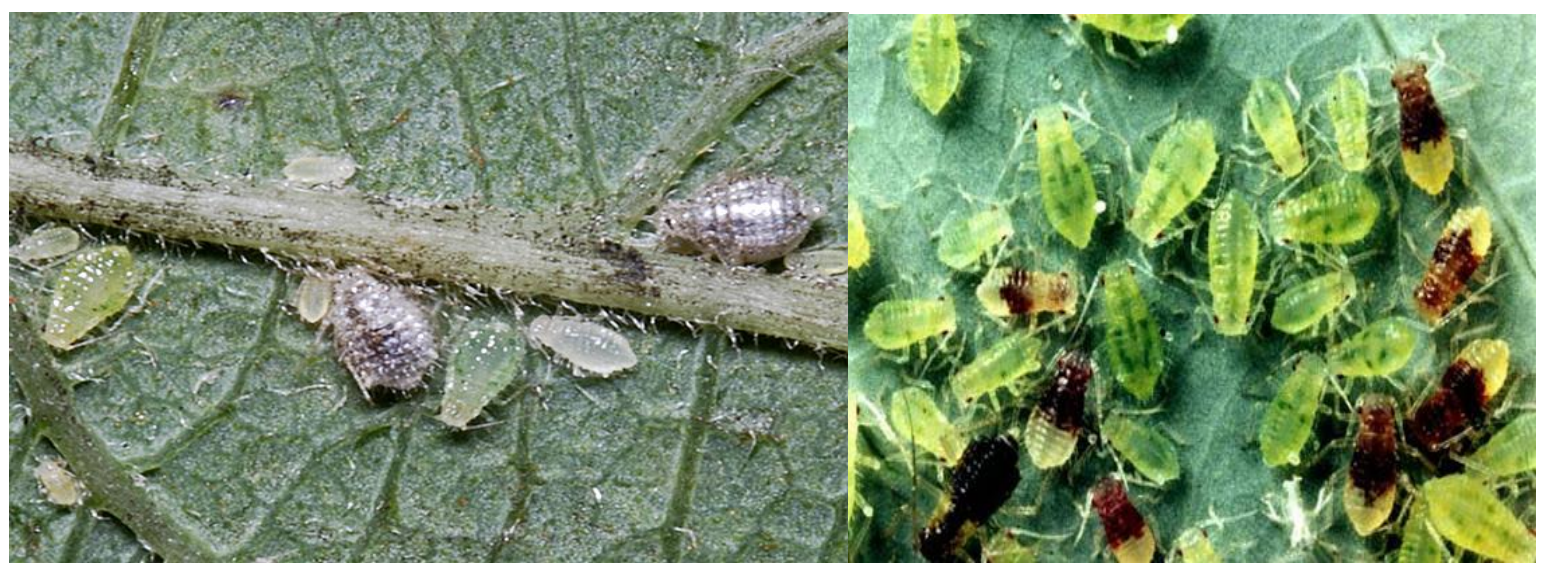

Figure 2. Brown shira - Chaitophorus capreae Mosl. and its larvae.

The larvae of the first age appear in late April and early May.They live in secret places formed by other insects. From spring to autumn, they multiply rapidly and cause serious damage to crops.

In September-October, they move to other trees by changing their food plants and living in dense colonies near their roots.

Clove is a medicinal plant and its use in the pharmaceutical industry is not recommended, given the production of drugs.

It is therefore advisable to organize the fight against its pests in biological, microbiological and methods. In recent years, a variety of chemicals have been used at great expense to produce a bountiful harvest, resulting in environmental pollution and the destruction of beneficial insects as well as pests.

This leads to a weakening of the entomofauna and an increase in both quantitatively and quantitatively, resulting in the resistance of harmful insects to the toxic chemicals used. It is no secret that the number of biolaboratories that reproduce beneficial insects has also been declining sharply in recent years, which has also led to a decrease in the number and quantity of beneficial insects in the entomofauna. Nowadays, a lot of attention is paid to organic agriculture all over the world.

Its main goal is to deliver environmentally friendly products without chemicals. The use of pesticides and anti-disease chemicals in vegetables, melons, berries, spices, as well as medicinal crops, which are the raw materials of the pharmaceutical industry, is especially harmful. Therefore, it is recommended to use "microbial" and non-traditional methods to protect such crops from various pests and diseases.

\section{CONCLUSION}

According to the scientific results of our research aimed at identifying pests of medicinal plants, these crops specialize in the production of worm (orexotvorka), nightshade, thrips, mint flea, cauliflower baridi, cauliflower juice, cauliflower stem valerian juice and valerian juice. pests were identified. 


\section{REFERENCES}

1. Ahmedov O., Ergashev A., Abzalov A., Yulchieva M., Medicinal plants cultivation technology and ecology Tashkent - 2009

2. Dusmanov I., Kholliev A. Control of pests and diseases of medicinal plants. Recommendation. 2015

3. Murdaxaev Yu.M. Medicinal plants native to Uzbekistan. - Tashkent: Fan, 1984.

4. Murodov S.A., Eromenko O.V. Identify important categories of insects. Toshkent, 1984. B. 23.

5. Nosyrev V.I., Drozdovskaya L.S., Bushkovskaya L.M. Integrated protection of medicinal crops is an important factor in increasing their yield // In the book: Protection of medicinal crops from pests, diseases and weeds. - Moscow, 1986. 